\title{
Factors affecting adult survival and inter-colony movement at the three South African colonies of Cape gannet
}

\author{
Greg Distiller ${ }^{1, *}$, Res Altwegg ${ }^{2}$, Robert J. M. Crawford ${ }^{3}$, Norbert T. W. Klages ${ }^{4}$, \\ Barbara Barham ${ }^{5}$ \\ ${ }^{1}$ Department of Statistical Sciences, University of Cape Town, Rondebosch 7701, South Africa \\ ${ }^{2}$ South African National Biodiversity Institute, P/Bag X7, Claremont 7735, South Africa; Animal Demography Unit, \\ Department of Zoology, University of Cape Town, Rondebosch 7701, South Africa \\ ${ }^{3}$ Department of Environmental Affairs, Private Bag X2, Rogge Bay 8012, South Africa \\ 4'Two Palms', 53 Clarendon St., Mount Pleasant 6070, South Africa \\ ${ }^{5}$ Penguin Datasystems, 2 Cotham Place, Trelawney Road, Bristol BS6 6QS, UK
}

\begin{abstract}
Marine systems are under pressure from both climate change and exploitation. While many of these ecosystems are inherently variable and hard to monitor, seabirds can be used as ecological indicators that provide early warning signals of deeper environmental change. The Agulhas-Benguela marine ecosystem around southern Africa has exhibited long-term changes in sea surface temperature, and the distribution of pelagic fish in this system has shifted. The Cape gannet Morus capensis is a seabird endemic as a breeding species to the Agulhas-Benguela ecosystem. Cape gannets breed at just 6 locations and are listed by the IUCN as Vulnerable. Knowledge of the survival and movements of a species is important for understanding of factors influencing its conservation. A random effects multistate capture-recapture model was used to estimate the annual survival probabilities and movement between colonies for adult birds at the 3 South African colonies of the species. The effects on survival of environmental and fisheries-related covariates were explored. Survival over the 20 yr period did not exhibit any long-term trend at the 2 southern colonies (Malgas and Bird Islands) but decreased at Lambert's Bay between 1996 and 2007. At all 3 colonies, adult birds showed a high degree of site fidelity. It may be that for Cape gannets, the primary effects of climate and fishing are on recruitment rather than on survival. The continued use of sub-optimal conditions by the west coast colonies has been referred to as an 'ecological trap' and necessitates the introduction of spatial considerations into fisheries management.
\end{abstract}

KEY WORDS: Cape gannets - Multistate capture-recapture models - Fisheries management · Ecological indicator $\cdot$ Seabirds $\cdot$ Survival

Resale or republication not permitted without written consent of the publisher

\section{INTRODUCTION}

Despite the fact that marine ecosystems are inherently variable and their biological components are difficult to monitor, a synthesis of long-term trends in the abundance, distribution and diversity of marine life confirms that marine systems are under pressure from both exploitation and climate change (Worm et al. 2010). Ecological indicators can greatly assist with the management of highly complex systems by providing easily understood signals that reflect the state of the system and can provide early warning signals of deeper environmental change (Piatt et al. 2007, Durant et al. 2009). 


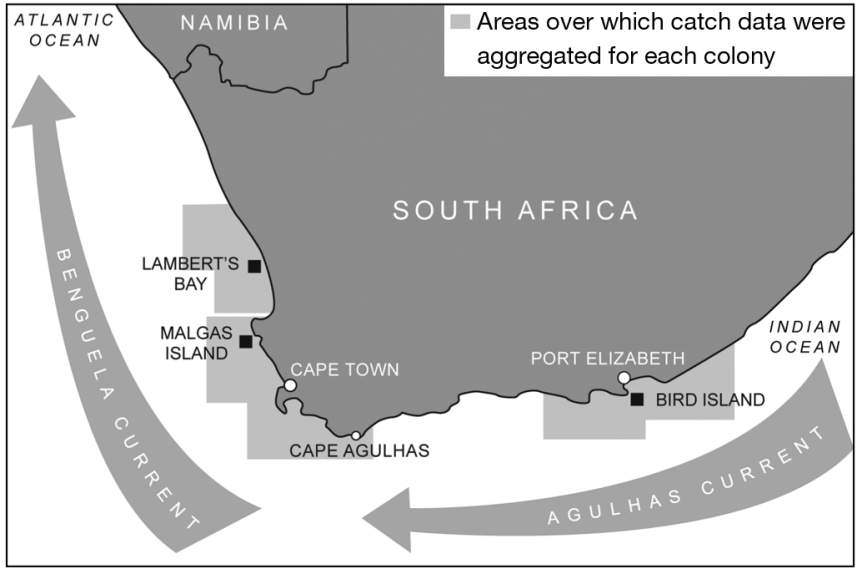

Fig. 1. Southern Africa, showing the location of the 3 gannet Morus capensis colonies, the Benguela and Agulhas currents, and the regions used to aggregate location-specific fish catch data: Lambert's Bay: $32.5^{\circ} \mathrm{S}, 18.18^{\circ} \mathrm{E}$; Malgas Island: $33.03^{\circ} \mathrm{S}$, $17.55^{\circ} \mathrm{E}$; Bird Island: $33.50^{\circ} \mathrm{S}, 26.17^{\circ} \mathrm{E}$

The Benguela upwelling ecosystem off south-western Africa is 1 of 4 major eastern boundary currents in the world's oceans and is a highly productive ecosystem which supports both sardine Sardinops sagax and anchovy Engraulis encrasicolus as the main forage fish species for several predators (Crawford 2007, Gremillet et al. 2008a). The Agulhas Current flows from the Mozambique Channel around the eastern and southern part of South Africa (Fig. 1). Both the Agulhas Current ecosystem and the southern Benguela ecosystem have exhibited long-term changes in sea surface temperature, with a cooling in the southern Benguela and a warming of the Agulhas Current over the past 2 decades (Roy et al. 2007, Rouault et al. 2009, 2010).

Seabirds and other predators at the top of the food chain are especially vulnerable to ecosystem perturbations and are often used as indicators for the state of oceanic ecosystems (Piatt et al. 2007, Durant et al. 2009, Rolland et al. 2010). In particular, predators that forage on a small number of key fish species should be better indicators for the state of the system than more generalist predators that can adapt their diet to suit what marine resources are available (Durant et al. 2009). The Convention for the Conservation of Antarctic Marine Living Resources has advocated the use of seabird parameters as ecological indicators, and some penguins are among species used as indicators for the Southern Ocean (Croxall et al. 1999, Durant et al. 2009).

The Cape gannet Morus capensis is a long-lived seabird, endemic as a breeding species to the Benguela and western Agulhas ecosystems, and its preferred food is sardine and anchovy when these fish are available (Berruti et al. 1993, Adams \& Klages 1999). The Cape gannet is thus a candidate species to be used as a sentinel of change in the region of its breeding distribution. Furthermore, Cape gannets are listed as Vulnerable (IUCN 2012) because they breed at just 6 locations off the coast of Namibia and South Africa and have shown a longterm decrease in numbers. Hence, there is also interest in the conservation of Cape gannets in their own right (Lewis et al. 2006, Crawford 2007, Pichegru et al. 2007, Crawford et al. 2008b). Fig. 1 shows the location of the 3 South African colonies of this species, namely Lambert's Bay, Malgas Island and Bird Island.

Over the past few decades there has been a clear shift in the breeding distribution of Cape gannets, with a decrease in numbers at the Namibian colonies, an increase at the Bird Island colony off the South African south coast and a decrease towards the end of our study at the 2 colonies off the South African west coast (Fig. 2; Crawford 2007, Crawford et al. 2008b). Similar distributional shifts to the south and east off southern Africa have been observed in several other seabird species (bank cormorant Phalacrocorax neglectus, crowned cormorant $P$. coronatus, Hartlaub's gull Larus hartlaubii, kelp gull $L$. dominicanus and swift tern Thalasseus bergii), and while local factors have played a part, the common pattern to the change in distributions during the same broad time span suggests a large-scale environmental influence (Crawford et al. 2008b).

In addition to the spatial shift in the breeding distributions of several seabirds, there have been shifts to

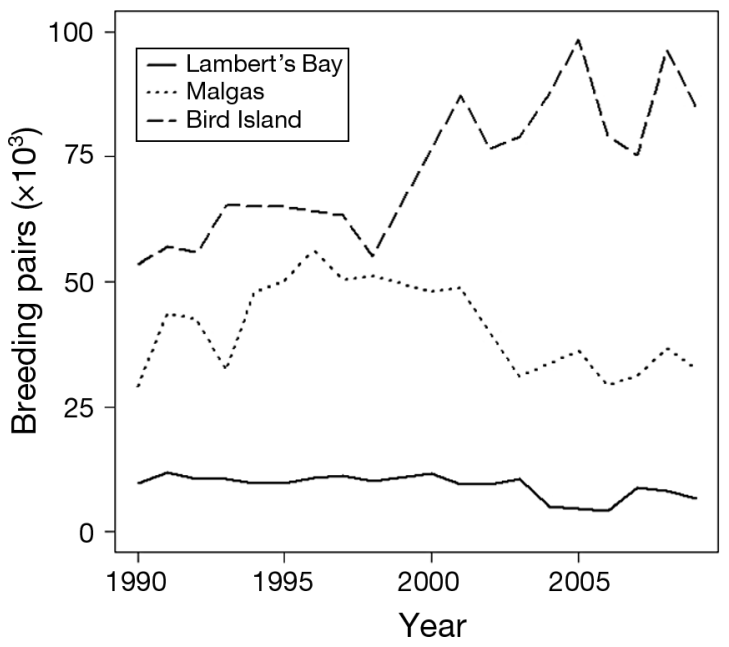

Fig. 2. Morus capensis. Trends in the number of breeding Cape gannets from 1990 to 2009 (in thousands). Modified from Crawford et al. (2007) 
the south and east in the distributions of spawning sardine and anchovy and of rock lobster Jasus lalandii (van der Lingen et al. 2005, Fairweather et al. 2006, Roy et al. 2007, Cockcroft et al. 2008, Coetzee et al. 2008a). These shifts have resulted in spatial mismatches between the breeding localities and prey of seabirds off South Africa's Western Cape.

Several studies have examined the role of climate on population dynamics. The most common climatic variables used include a large-scale index of oceanic conditions (such as the Southern Oscillation Index, $\mathrm{SOI}$, or the North Atlantic Oscillation, NAO), more localised measures such as sea surface temperature (SST) and some measure of prey availability (Frederiksen et al. 2004, Sandvik et al. 2005, Rolland et al. 2010).

Industrial fisheries can affect seabirds both directly and indirectly (Ormerod 2003, Frederiksen et al. 2004, Gremillet \& Boulinier 2009), where the primary indirect effect is believed to operate through a reduction of the availability of prey (Frederiksen et al. 2004, Crawford et al. 2007, Gremillet \& Boulinier 2009). Commercial purse-seine fisheries for sardine and anchovy started off Namibia and South Africa after World War II (van der Lingen et al. 2005, Fairweather et al. 2006, Crawford 2007), and they potentially affect Cape gannets by competing for the same food resources.

Marine food webs are affected by both bottom-up and top-down processes whereby climate tends to work through the former and fishing can have an important top-down effect (Cury et al. 2000). The combination of these 2 factors can have severe consequences on seabird populations, yet it is often difficult to disentangle their effects (Frederiksen et al. 2004, Rolland et al. 2008, Gremillet \& Boulinier 2009, Rolland et al. 2010). It is believed that the spatial shift in the distribution of sardine and anchovy in the southern Benguela system was caused by such a combination of factors (Gremillet et al. 2008a, Gremillet \& Boulinier 2009) and could indicate an ecological regime shift that is likely to have significant consequences for the local marine ecosystem (Gremillet et al. 2008a).

The change in the abundance of prey can have a substantial, rapid effect on predators like the Cape gannet, whose mobility is limited while rearing young and who display strong site fidelity tendencies (Crawford 2007, Crawford et al. 2008a, Durant et al. 2009). A change in prey availability may influence the decision to breed and can play a major role in breeding success, can affect survival and can influence inter-colony movements (Crawford \& Dyer
1995, Crawford et al. 2008a, 2011). Consequently, the change in the distribution of sardine and anchovy is thought to be largely responsible for the changes observed in the gannet colonies. However, the contribution of local demographic rates and movement between colonies is unclear (Lewis et al. 2006, Crawford 2007, Pichegru et al. 2007). Understanding the exchange of individuals among colonies of seabirds as well as spatial shifts in their breeding populations is one of the major objectives of seabird ecology (Gremillet \& Boulinier 2009).

The objectives of this research were firstly to obtain estimates for adult survival and of movement between colonies of adult Cape gannets over a $20 \mathrm{yr}$ period (1989 to 2009), and secondly to examine environmental and fisheries related covariates in order to understand potential factors driving the gannet population dynamics. These results also help inform what is happening with the broader marine system off southern Africa.

\section{MATERIALS AND METHODS}

\section{Field methods}

The data consist of 30333 captures (including 11434 recaptures) of 18898 ringed adult gannets between 1989 and 2009 from gannet colonies off the west coast (5132 at Lambert's Bay and 6534 at Malgas Bay) and south coast (6907 at Bird Island) of South Africa, as well as data on 187 dead recoveries for the same time period. There were 276 birds that were seen at more than 1 colony. At all 3 colonies, banding of nestling and adult gannets took place in late summer towards the end of the breeding season. For this analysis, birds banded as nestlings were only included at first recapture as adults, and birds originally banded before 1989 were included from their first recapture during the period considered here. Recaptures of banded birds took place throughout the year but mainly during the September to March breeding period, when birds congregate at colonies (Staverees et al. 2008). Birds were caught using a hook on the end of a pole, as described by Berruti et al. (1993).

\section{Statistical analyses}

Program MARK ver. 6.0 (White \& Burnham 1999) was used to fit open population capture-recapture models (Lebreton et al. 1992) in order to estimate adult survival for the Cape gannet. These models 
account for both survival and detection probability (detection is also referred to as recapture) since a bird may survive but not be detected during the samling process (see supplement for a glossary of statistical terms). Two key underlying assumptions of capture-recapture models are that all individuals in a group have equal survival and detection probabilities. However, in this context it is likely that these assumptions are violated because of the following. (1) Birds breeding on the edges of the colony were more likely to be captured because most searches for banded birds were made around the edges of colonies, since it is disruptive to venture into the middle of the colonies, and birds tend to nest in the same place from year to year (Klages 1994); consequently, a trap-dependent effect was expected whereby a bird caught during the previous year was more likely to be caught again than one that was not caught in the previous year. (2) During the sampling occasion, transient individuals tend to be present, i.e. non-resident birds that are unlikely to be found in that location in the future. Ignoring the presence of such transients can lead to negative bias in survival estimates.

Initially, the Cormack-Jolly-Seber (CJS) model was used on the recapture data only, with time-varying parameters for survival and recapture. Program U-Care (Choquet et al. 2009) was used to assess the goodness-of-fit of this general model to each colony separately (referred to as single-state models). All colonies produced strong signals for both a transient effect and a trap-dependent effect. Consequently, an additive transient effect (Pradel et al. 1997) was included as well as individual covariates that indicated whether an individual was captured during the previous year. Goodness-of-fit of this modified model was then assessed using the median-ĉ procedure in program MARK, and there were no remaining signs of over dispersion (estimates ranged from 1.05 to 1.1). The recovery data were then incorporated and a model with time-varying parameters for both survival and recapture (with constant recovery and fidelity) was fitted, using the parameterisation suggested by Burnham (1993). Including recovery data into the analysis allows both the recovery rate and a fidelity parameter to be estimated, in addition to survival and recapture rates. The fidelity parameter represents the likelihood of an individual remaining in the colony and hence allows the estimation of 'true' mortality rather than 'apparent' mortality. At this stage, the model included all colonies in a multistate model, where the states represent the islands at which breeding occurs and the transition probabilities between the states represent movement between islands.
A number of years in the time series had very little information, i.e. very few recaptures. This resulted in parameter estimates for those years occurring at the boundary (usually 1 ) and often with a standard error of 0 . Consequently, a model with random effects was used so that the years with sparse data could 'borrow' information from other years (Francis \& Saurola 2009). The Markov Chain Monte Carlo (MCMC) procedure within MARK was used to fit this randomeffects model. The default MARK parameter settings were used: 4000 'tuning' samples, 1000 'burn-in' samples and 10000 samples to store. The model was parameterised so that the random effects represented yearly random deviations around the mean for both survival and recapture probabilities for each colony. We further estimated the correlation $(\rho)$ in survival among colonies to examine how synchronous fluctuations in survival were over time. Uninformative priors were specified for all parameters with the exception of the means for the survival and recapture hyperdistributions. These hyperdistributions were given a mean of 0 and a very small variance (0.001) in order to ensure that the random effects estimated yearly deviations around the mean. The variances were given the default priors, namely that $1 / \sigma^{2}$ followed a gamma distribution with alpha $=$ 0.0001 and beta $=0.0001$, and $\rho$ followed a uniform distribution between -1 and 1 . It took $30 \mathrm{~d}$ to run a single chain on an Intel Core 2 Duo PC with 2 GB of RAM, and hence multiple chains were not run. Convergence statistics for multiple chains could therefore not be used, but trace plots were examined and did not suggest convergence problems. Furthermore, the parameter estimates from the multistate model were similar to those from the single-state fixed effects models, which suggests that the MCMC estimates are stable.

The effects of various covariates were explored by fitting single-state models to each island. An analysis of deviance approach (Skalski et al. 1993) was used to assess the impact of the covariates by calculating the proportion of year to year variance that was explained by a particular covariate. These covariate models were therefore fixed effects models with the full parameterisation including year-specific estimates for all years.

\section{Environmental covariates}

In this study, the following variables were selected to investigate the role of the environment on survival rates: the Southern Oscillation Index (SOI), sea sur- 
face temperature (SST) and the combined biomass of sardine and anchovy (Biomass) recorded during annual surveys of these species conducted in November.

An analysis of SST in the marine environment around South Africa from 1982 to 2009 found that the primary signal for environmental change was in the winter months, with cooling on the west coast, south coast and in the Port Elizabeth region, and warming for the Agulhas system to the south (Rouault et al. 2010). Consequently, the monthly data for both SOI and SST were aggregated over the winter months (April to August). Survival of adult Cape gannets is likely to be influenced by processes that happen during both breeding (summer) and non-breeding (winter) periods. In summer, breeding birds need to feed chicks. In winter, for example, storms may result in periods of several days when fish may be difficult to locate.

Being a large-scale factor, the values used for SOI were common to all islands, whereas the more localised SST factor was calculated by aggregating domain-specific areas for the west coast, the south coast and the Port Elizabeth region (for further details see Rouault et al. 2010).

The estimated spawner biomasses for sardine and anchovy, obtained from hydro-acoustic surveys (Coetzee et al. 2008b), were combined because these fish species have generally contributed the bulk of the food of Cape gannets (Hockey et al. 2005). This variable (Biomass) had a spatial element, as it was formed for the west coast by using values for biomass west of Cape Agulhas, and for the south coast by using values for biomass east of Cape Agulhas. The proportion of the overall biomass of sardine and anchovy found east of Cape Agulhas (\% Biomass) was used as a covariate on the movement parameters. The aim was to explore whether the movement of birds between colonies tracked the movement of pelagic fish.

\section{Fishing covariates}

Our analysis explored the effect on adult survival of annual catch and the time in months that it took the industry to achieve $50 \%$ of the annual quota (50\% Time).

Catch data for both sardine and anchovy were provided per year and per pelagic fishing block (PFB) by the Department of Agriculture, Forestry \& Fisheries. Information on the foraging range of gannets from each colony (Pichegru et al. 2009) was used to guide which PFBs to include in the aggrega- tion of location-specific covariates for different colonies (Fig. 1). The data for sardine and anchovy, the 2 preferred prey species, were combined to give a location-specific indication of the combined annual catch. Even though the gannets' feeding range varies within and among years (Mullers \& Navarro 2010), we think that the chosen PFBs are a good representation of the main foraging areas of breeding birds. Since fish densities on the west coast are spatially correlated, this assumption is unlikely to affect our results.

Fishing quotas for sardine and anchovy in South Africa are based on 2 surveys: biomass estimates are obtained in November and used to set the initial quotas for the following year; recruitment surveys take place in May and are used to adjust the quotas upwards if better than expected recruitment is observed. The surveys estimate fish biomass with an inevitable amount of uncertainty, and quotas may therefore be too high or too low in relation to the true fish abundance in a given year. The speed at which the industry reaches its allowed quota (and whether the quota is reached at all) depends on various factors, including bad weather that hampers fishing and mechanical problems with the boats. However, it may also reflect fish availability, e.g. fish may be far removed from factories, and the degree to which fish biomass may have been over- or underestimated. We hypothesised that gannet survival is lower in years when the fishery struggles to fill its quota.

A covariate that represents how easy (or difficult) it was for the industry to fill its quota (for sardine and anchovy combined) in a particular year was therefore created by using the month by which $50 \%$ of the quota was achieved. As the full quota was often not reached over the course of our study, we chose the time taken to reach $50 \%$ of the quota, which produced sufficient variability for the years in question.

\section{Diet}

Sardine is the preferred prey species of Cape gannets (Adams \& Klages 1999) and the presence of lipid-rich fish prey (including sardine) in the diet has been shown to be associated with improved chick growth (Mullers et al. 2009). The percentage of sardine in the diet was examined in the covariate models. At Lambert's Bay and Malgas Island, diet samples were collected monthly; at Bird Island, most samples were collected during the gannet breeding season. Adults returning to the islands were caught 

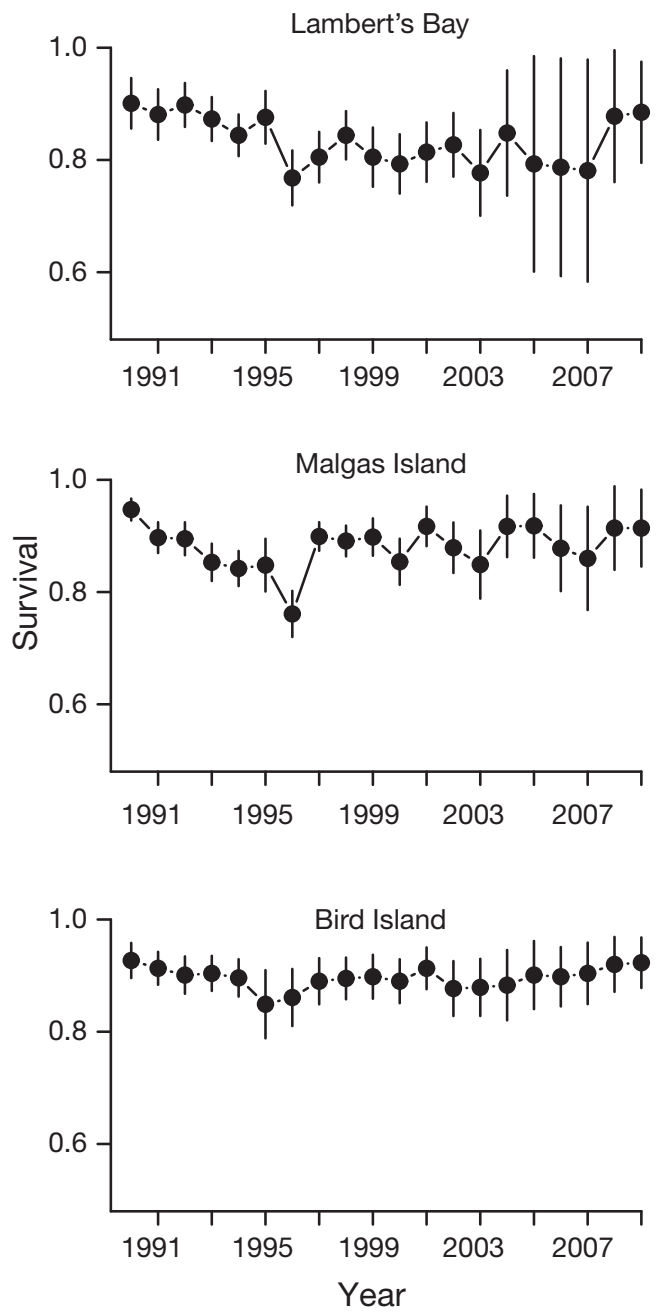

Fig. 3. Morus capensis. Survival estimates of Cape gannets with $95 \%$ Bayesian credible intervals from the multi-state model for adult resident gannets from 1990 to 2009. See Table S1 in the supplement at www.int-res.com/articles/ suppl/m461p245_supp.pdf for more detail

using a hook attached to a pole and inverted over a bucket, when they often regurgitated their last meal (Berruti et al. 1993). They were then released. If birds did not regurgitate food within about $1 \mathrm{~min}$, they were also released.

\section{RESULTS}

\section{Survival and movement}

Annual estimates of survival, and 95\% credible intervals, obtained from the multistate model which accounts for movement between colonies, are shown in Fig. 3.
At Lambert's Bay, the survival estimates for recent years have large credible intervals due to a scarcity of data for those years. The entire colony abandoned the island in the 2005/06 breeding season after being severely disturbed by Cape fur seals Arctocephalus pusillus pusillus, which resulted in reduced field work there around this time (Crawford et al. 2007). Average survival was highest for Bird Island $(0.90 \pm 0.004[\mathrm{SE}])$, slightly lower for Malgas $(0.88 \pm 0.009)$ and lowest for Lambert's Bay $(0.83 \pm 0.009)$. Survival tended to be positively correlated across colonies ( $\rho$ ranged from 0.35 to 0.42 ), but the correlation coefficients were estimated poorly, and all of them had credible intervals that included 0 . Survival showed no long-term trend at Malgas and Bird Islands, although it decreased substantially at Malgas Island in 1996. Survival decreased at Lambert's Bay between 1996 and 2007, before recovering again in 2008 and 2009. However, as mentioned above, the credible intervals for estimates at Lambert's Bay for 2008 and 2009 indicate a large degree of uncertainty. The process variance in survival was estimated at $0.489 \pm 0.145$ for Lambert's Bay, $0.467 \pm 0.112$ for Malgas Island and $0.287 \pm 0.117$ for Bird Island.

There was little movement of adult gannets between the colonies, particularly to and from Bird Island (Table 1). The greatest amount of movement was between the 2 west coast colonies, Lambert's Bay and Malgas Island. Years with relatively high proportions of biomass east of Cape Agulhas were associated with lower movement between these 2 colonies, whereas movement from the 2 west coast colonies to Bird Island on the south coast was not significantly related to the location of fish biomass. However, movement from Bird Island to Malgas Island was negatively related to the location of fish biomass, with fewer birds moving west when most fish were located in the east.

\section{Recapture and recovery}

Recapture rates were on average highest for Lambert's Bay $(0.25 \pm 0.03)$, intermediate for Malgas Island $(0.20 \pm 0.02)$ and lowest for Bird Island $(0.06 \pm 0.01)$. Recovery rates were constant in the model and ranged from $0.01 \pm 0.002$ for Lambert's Bay, through $0.02 \pm 0.002$ for Bird Island to $0.004 \pm$ 0.001 for Malgas Island. The full results from the multistate model are shown in Table S1 in the supplement at www.int-res.com/articles/suppl/m461 p245_supp.pdf. 


\section{Covariate models}

Possible causes of variation in survival at each colony were explored using single-state models with covariates. Table 2 summarises the results of the analysis of deviance from the covariate models, and Tables S2 and S3 in the supplement summarise the $\beta$ estimates from the covariate models and the model selection details including Akaike weights, deviances and delta Akaike information criteria (AICs). Note that there was no support for anything other

Table 1. Morus capensis. Estimates of adult movements from 1989 to 2009 among the 3 Cape gannet colonies in South Africa and their relationship to the location of fish biomass (\% Biomass). Movement was modelled as the probability of transitioning between colonies. For example, the mean $\psi_{\text {(Lam-Malgas) }}$ of 0.018 means that on average there is a $1.8 \%$ probability of an individual bird moving from Lambert's Bay to Malgas island at the end of a particular year. The mean $\psi$ s are the means of the time-dependent movement parameters. The $\beta$ coefficient is the partial regression coefficient for the effect of the location of fish biomass (i.e. the proportion of sardine and anchovy biomass east of Agulhas) on movement. Note that the $\beta$ estimate is on the logit scale and therefore it is difficult to interpret the absolute value of the estimate, although a positive coefficient increases the probability of movement and vice versa. SD is the standard deviation of the partial regression coefficient among years with the $95 \%$ credible interval in brackets. Lam: Lambert's Bay, BI: Bird Island

\begin{tabular}{|lcccl|}
\hline Movement & Mean & SE & \% Biomass $\beta$ & \multicolumn{1}{c|}{ SD } \\
\hline$\psi_{\text {(Lam-Malgas) }}$ & 0.018 & 0.0013 & -2.304 & $0.615(-3.49:-1.08)$ \\
$\psi_{\text {(Lam-BI) }}$ & 0.002 & 0.0001 & -1.954 & $1.439(-4.82: 0.80)$ \\
$\psi_{\text {(Malgas-Lam) }}$ & 0.007 & 0.0006 & -2.716 & $0.878(-4.65:-0.95)$ \\
$\psi_{\text {(Malgas-BI) }}$ & 0.002 & 0.0002 & -2.548 & $1.407(-5.37: 0.12)$ \\
$\psi_{\text {(BI-Lam) }}$ & $0.001<0.0001$ & -0.37 & $0.733(-2.87: 2.32)$ \\
$\psi_{\text {(BI-Malgas) }}$ & $0.001<0.0001$ & -2.545 & $0.733(-5.34:-0.01)$ \\
\hline
\end{tabular}

than the fully time-dependent model on all colonies. This does not mean that the covariates are unimportant, as with large sample sizes and high temporal variance, AIC tends to favour the fully time-dependent model (Link 1999). We therefore concentrate on analyses of deviance next to estimate what proportion of the temporal variance is explained by the covariates.

The percent sardine in the gannets' diet did not explain much of the variation in survival for the west coast colonies, but it explained almost $18 \%$ for Bird

Island. Interestingly, the $\beta$ coefficients for diet were negative for all 3 islands, suggesting that an increase in the proportion of sardine eaten is associated with lower survival. This counterintuitive result is addressed further in the 'Discussion'.

A higher winter SST around Lambert's Bay was associated with higher survival and explained over $41 \%$ of the variation in survival at that colony. SST only explained $9 \%$ of the variation at Malgas Island and $7 \%$ at Bird Island, but the direction of these effects was also positive. The large scale SOI variable explained around $12 \%$ of the variation at Lambert's Bay but only a small fraction at the other 2 colonies. The influence of biomass on variation in survival was weak for all islands.

The longer it took the industry to reach $50 \%$ of the annual quota, the worse survival was for adult gannets on all 3 islands. This covariate explained only $4 \%$ of the variation in survival at Malgas, but explained more (11\%) at Bird Island and $33 \%$ at Lambert's Bay. Similarly, annual catch explained just $5 \%$ of the variation in

Table 2. Morus capensis. Results from the analysis of deviance that calculates the percentage of variance in survival explained by the different covariates on the 3 South African Cape gannet colonies from 1989 to 2009. SST(W): sea surface temperature aggregated over the winter months for the appropriate area; SOI(W): Southern Oscillation Index averaged over the winter months; Time to $50 \%$ : time in months that it took the industry to achieve at least $50 \%$ of the quota

\begin{tabular}{|c|c|c|c|c|c|c|}
\hline \multirow[t]{2}{*}{ Model } & \multicolumn{2}{|c|}{ Lambert's Bay } & \multicolumn{2}{|c|}{ Malgas Island } & \multicolumn{2}{|c|}{ Bird Island } \\
\hline & Deviance & $\%$ Explained & Deviance & $\%$ Explained & Deviance & \% Explained \\
\hline Full time dependence & 23297.82 & 100 & 28191.22 & 100 & 16304.87 & 100 \\
\hline Constant over time & 23421.49 & 0 & 28351.24 & 0 & 16374.90 & 0 \\
\hline \multicolumn{7}{|l|}{ \% Sardine in diet } \\
\hline Diet & 23413.36 & 6.6 & 28344.90 & 4.0 & 16362.46 & 17.8 \\
\hline \multicolumn{7}{|c|}{ Environmental covariates on adult gannet survival } \\
\hline $\operatorname{SST}(\mathrm{W})$ & 23370.15 & 41.5 & 28336.84 & 9.0 & 16369.70 & 7.4 \\
\hline SOI(W) & 23406.1 & 12.4 & 28343.24 & 5.0 & 16372.95 & 2.8 \\
\hline Biomass & 23414.37 & 5.8 & 28343.44 & 4.9 & 16373.23 & 2.4 \\
\hline \multicolumn{7}{|c|}{ Fisheries covariates on adult gannet survival } \\
\hline Time to $50 \%$ & 23380.92 & 32.8 & 28344.4 & 4.3 & 16366.96 & 11.3 \\
\hline Annual catch & 23396.56 & 20.2 & 28343.98 & 4.5 & 16365.27 & 13.8 \\
\hline
\end{tabular}


annual survival at Malgas Island, $14 \%$ at Bird Island and $20 \%$ at Lambert's Bay. Interestingly, the direction of the effect of annual catch was positive (albeit small) for the west coast colonies but negative for Bird Island.

\section{DISCUSSION}

We examined the survival and movements of adult Cape gannets at their 3 South African colonies, which currently comprise $90 \%$ of the global population of this species (Crawford et al. 2007). Between 1990 and 2009, adult survival fluctuated around $0.90 \mathrm{yr}^{-1}$ at Bird Island, $0.88 \mathrm{yr}^{-1}$ at Malgas Island and averaged $0.83 \mathrm{yr}^{-1}$ at Lambert's Bay. These estimates correspond well with previously published survival estimates for the species at Lambert's Bay and Malgas Island (Altwegg et al. 2008). It is interesting that the mean survival was lowest at the northernmost colony, Lambert's Bay. This is attributable to a decreased survival at this colony between 1996 and 2007 (Fig. 3), a period that coincides with southeastward displacements of most spawning sardine and anchovy from the west coast of South Africa to the south coast (Roy et al. 2007, Coetzee et al. 2008a). These displacements would have placed forage fish increasingly distant from gannets at Lambert's Bay in the austral summer, the main breeding period, and may have reduced survival. Survival decreased markedly at both Lambert's Bay and Malgas Island in 1996, when the abundance of anchovy off South Africa plummeted to its lowest recorded level. Furthermore, at Lambert's Bay the island is joined to the mainland, which has allowed access to it by mainland predators (Cape Nature, Department of Environmental Affairs South Africa, unpublished records). The colony is also visited by many tourists, although they are unlikely to influence survival.

The estimated movement rates of adults among colonies were low, especially between the 2 west coast colonies and that on the south coast. However, recapture effort at Bird Island in the south was low after the mid-1990s, at the time that stocks of prey fish shifted south and east and movements of birds to the east might have been anticipated. Furthermore, once breeding, adult Cape gannets are faithful to nest sites (Klages 1994). Hence, not much movement of adult birds between colonies would be expected. It is more likely that immature and pre-breeding adults would move to other colonies and so it is possible that some immigration of juveniles has contributed to the observed growth of the colony at Bird Island, although there is insufficient information to examine this possibility. It is interesting that little movement of birds between the 2 west coast colonies was detected when most fish had an eastern location, possibly suggesting that immigration to colonies is minimal when food is scarce nearby.

Adult survival is a crucial parameter in the population dynamics of long-lived species such as Cape gannets and is believed to be canalized against climatic variation (Gaillard \& Yoccoz 2003), i.e. it is expected to be the demographic parameter least affected by climate (Sandvik et al. 2005, Gremillet \& Boulinier 2009, Rolland et al. 2010). While various studies have found a stronger link between climate and breeding success rather than survival, associations between seabird survival and climate have been reported (Frederiksen et al. 2004, Velarde et al. 2004, Sandvik et al. 2005, Rolland et al. 2008). In most cases, SST seems to explain variation in survival better than large-scale indicators like SOI or NAO.

The lack of a consistent association between the SOI and survival in this study is therefore expected and mirrors similar findings reported elsewhere (Frederiksen et al. 2004, Rolland et al. 2008, 2010). It is also not surprising that SST does not consistently explain survival when one considers the spatial mismatch between pelagic fish and zooplankton that has been recently reported in the Benguela system, and the fact that SST is primarily a proxy for primary productivity whereas top predators feed several trophic levels up the food chain (Gremillet et al. 2008a, Gremillet \& Boulinier 2009, Boyce et al. 2010).

The fact that SST around the west coast managed to explain over $40 \%$ of the variation in survival on Lambert's Bay is interesting. Gremillet et al. (2008a) noted that the at-sea distributions of Cape gannets off South Africa's west coast were related to areas of low SST and high primary productivity, but not to the distributions of anchovy which at the time were predominately on the south coast of South Africa. However, in most years, anchovy and sardine contribute the bulk of the diet of gannets at Lambert's Bay (Berruti et al. 1993, Crawford et al. 2011). The positive effect of SST on survival suggests that long-term cooling in the Benguela during winter could be detrimental to the Lambert's Bay colony, although the mechanism for this is unclear. It seems more likely that summer displacement of prey away from the colony influenced the decrease in survival of adult gannets at Lambert's Bay. A similar effect of SST on 
Cape gannets at Malgas Island was not evident; Cape gannets at Malgas Island have a more diverse diet than those at Lambert's Bay, feeding to a greater extent on the oceanic saury Scomberesox saurus and hakes Merluccius spp. that are discarded by fisheries.

The annual catch variable is meant to represent the effect of competition for prey by the purse-seine fishery and the gannets. However, the annual quota is based on an estimate of fish abundance so that higher catches should be taken in years where there are more fish. Consequently, if the estimates of fish abundance are accurate, there should not be much of an effect of fish catch on the gannets. Therefore, a negative effect could indicate a quota that is set too high and results in the removal of too much prey from the ocean with detrimental consequences for the birds.

The contrasting results between the west and the south coast are interesting. It is possible that the positive effect of annual catch seen off the west coast is a reflection of higher fish availability on the west coast benefiting both fishers and gannets, whereas the negative effect on the south coast indicates a real impact of the fishery on sardine available to the gannets. Around 2005, anchovy and sardine were scarce along the west coast, resulting in lower catches, and a decreased contribution to the diet of gannets, of both species (Gremillet et al. 2008a). After 2000, the contribution of sardine to the diet of Cape gannets at Bird Island on the south coast increased markedly and there was also a substantial increase in the catch of sardine in the region (Crawford et al. 2009). However, most sardine and anchovy remained a considerable distance to the west of Bird Island (Shabangu et al. 2011).

The interpretation of the negative effect of the $50 \%$ time variable is not straightforward due to the fact that several factors can potentially affect the fishing industry's ability to fill the quota. It seems though that in years when it was difficult for the fishery to catch the allocated quotas, it was also difficult for Cape gannets to find prey, probably with detrimental consequences to their survival. Furthermore, gannets should experience less competition for their preferred prey species at the start of their breeding season in years when the quota is achieved relatively early on (Gremillet et al. 2010). The link between quota fulfilment and survival of adult Cape gannets merits further investigation.

The diet covariate had its greatest influence on adult survival at Bird Island. However, there and on the west coast, increased proportions of sardine in the diet were associated with decreased survival. This is a counter-intuitive result that may be spurious, or it may indicate that alternative food that 'buffers' occasions when sardines are not available to gannets, e.g. they are too deep in the water column or too far from the breeding colonies or when gannets are unable to find sardines, is beneficial.

It may be that for Cape gannets, the primary effects of climate and fishing are on recruitment rather than adult survival, which has not shown large fluctuations. Hence, the breeding and juvenile survival components could be the primary drivers of recently observed changes in numbers at South Africa's gannet colonies, even though a recent study showed that breeding success was actually higher in a declining Namibian colony than at Malgas Island (Mullers \& Navarro 2010). The eastward shift in pelagic fish resulted in birds at Malgas Island feeding substantially on fishery wastes, whereas gannets at the increasing Bird Island colony fed mainly on natural prey, which could be another factor explaining the decline in the west coast colonies and the increase at the south coast colony (Pichegru et al. 2007, Mullers et al. 2009). This hypothesis seems plausible when considering that population growth is driven by food availability during the breeding season (Lewis et al. 2006) and that a dietary shift often has negative consequences for seabird breeding success (Gremillet \& Boulinier 2009). In fact, the continued use of suboptimal conditions by the west coast colonies has been referred to as an 'ecological trap' (Gremillet \& Boulinier 2009). The decreased survival of Cape gannets at Lambert's Bay over a 10 yr period suggests that survival may be influencing trends at some gannet colonies. It is also possible that the recent high survival rates at Bird Island are partially attributable to the availability of high-quality food to birds at that colony throughout the year.

Recent intensive predation of Cape gannet fledglings by Cape fur seals has also reduced gannet production on the west coast (Makhado et al. 2006). Furthermore, most of the fish factories in South Africa are located near gannet colonies in the Western Cape, and fishers attempt to make catches as close to the factories as possible despite the reduction in food availability in the west (van der Lingen et al. 2005, Fairweather et al. 2006, Crawford et al. 2008a, Gremillet et al. 2008a,b), thereby further depleting densities of forage fish in the vicinity of Cape gannet colonies off South Africa's west coast. For this reason, there is a need to introduce spatial considerations into fisheries management (van der Lingen et al. 2005, Crawford et al. 2008a). 
Acknowledgements. We thank C. van der Lingen, L. Shannon and M. Rouault for helpful discussions. The Department of Agriculture, Forestry \& Fisheries provided fish catch, quota and biomass data. We thank all those who assisted with banding and recapture of gannets over many years, including B.M. Dyer, A.B. Makhado and L. Visagie, and the South African Bird Ringing Unit (SAFRING) for collating the banding information. Access to and accommodation at the Cape gannet colonies was facilitated by (1) Cape Nature, (2) the Department of Environmental Affairs, (3) SANParks and (4) the South African National Defence Force. R.A. was supported by a grant from the National Research Foundation (NRF). The banding, recapture and recovery of Cape gannets was also supported by an NRF grant under its Seachange programme.

\section{LITERATURE CITED}

Adams NJ, Klages NTW (1999) Foraging effort and prey choice in cape gannets. S Afr J Mar Sci 21:157-163

> Altwegg R, Crawford RJM, Underhill LG, Williams AJ (2008) Long-term survival of de-oiled Cape gannets Morus capensis after the Castillo de Bellver oil spill of 1983. Biol Conserv 141:1924-1929

> Berruti A, Underhill LG, Shelton PA, Moloney C, Crawford RJM (1993) Seasonal and interannual variation in the diet of two colonies of the Cape gannet Morus capensis between 1977/1978 and 1989. Colon Waterbirds 16: 158-175

Boyce DG, Lewis MR, Worm B (2010) Global phytoplankton decline over the past century. Nature 466:591-596

Burnham K (1993) A theory for combined analysis of ring recovery and recapture data. In: Lebreton JD, North $\mathrm{P}$ (eds) Marked individuals in the study of bird population. Birkhäuser Verlag, Basel, p 199-213

Choquet R, Reboulet AM, Pradel R, Gimenez O, Lebreton JD (2009) U-care: utilities for performing goodness of fit tests and manipulating capture-recapture data. Ecography 32:1071-1074

> Cockcroft AC, van Zyl D, Hutchings L (2008) Large-scale changes in the spatial distribution of South African west coast rock lobsters: an overview. Afr J Mar Sci 30: 149-159

Coetzee J, van der Lingen C, Hutchings L, Fairweather TP (2008a) Has the fishery contributed to a major shift in the distribution of South African sardine? ICES J Mar Sci 65: 1676-1688

Coetzee JC, Merkle D, de Moor CL, Twata NM, Barange M, Butterworth DS (2008b) Refined estimates of South African pelagic fish biomass from hydro-acoustic surveys: quantifying the effects of target strength, signal attenuation and receiver saturation. Afr J Mar Sci 30: 205-217

> Crawford RJM (2007) Food, fishing and seabirds in the Benguela upwelling system. J Ornithol 148(Suppl 2): 253-260

> Crawford RJM, Dyer BM (1995) Responses by four seabirds to a fluctuating availability of Cape anchovy Engraulis capensis off South Africa. Ibis 137:329-339

> Crawford RJM, Dundee BL, Dyer BM, Klages NTW, Meyer MA, Upfold L (2007) Trends in numbers of Cape gannets (Morus capensis), 1956/57-2005/06, with a consideration of the influence of food and other factors. ICES J Mar Sci 64:169-177
Crawford RJM, Sabarros PS, Fairweather T, Underhill LG, Wolfaardt AC (2008a) Implications for seabirds off South Africa of a long-term change in the distribution of sardine. Afr J Mar Sci 30:177-184

> Crawford RJM, Tree AJ, Whittington PA, Visagie J and others (2008b) Recent distributional changes of seabirds in South Africa: Is climate having an impact? Afr J Mar Sci 30:189-193

Crawford RJM, Whittington PA, Martin AP, Tree AJ, Makhado AB (2009) Population trends of seabirds breeding in South Africa's Eastern Cape, and the possible influence of anthropogenic and environmental change. Mar Ornithol 37:159-174

- Crawford RJM, Altwegg R, Barham BJ, Barham PJ and others (2011) Collapse of South Africa's penguins in the early 21st century. Afr J Mar Sci 33:139-155

> Croxall JP, Reid K, Prince PA (1999) Diet, provisioning and productivity responses of marine predators to differences in availability of Antarctic krill. Mar Ecol Prog Ser 177: 115-131

Cury P, Bakun A, Crawford RJM, Jarre A, Quiones RA, Shannon LJ, Verheye HM (2000) Small pelagics in upwelling systems: patterns of interaction and structural changes in wasp-waist ecosystems. ICES J Mar Sci 57: 603-618

Durant JM, Hjermann DO, Frederiksen M, Charrassin JB and others (2009) Pros and cons of using seabirds as ecological indicators. Clim Res 39:115-129

Fairweather TP, van der Lingen CD, Booth AJ, Drapeau L, van der Westhuizen JJ (2006) Indicators of sustainable fishing for South African sardine Sardinops sagax and anchovy Engraulis encrasicolus. Afr J Mar Sci 28: $661-680$

Francis CM, Saurola P (2009) Estimating demographic parameters from complex data sets: a comparison of Bayesian hierarchical and maximum-likelihood methods for estimating survival probabilities of tawny owls, Strix aluco in Finland. In: Thomson DL, Cooch EG, Conroy MJ, Patil GP (eds) Modeling demographic processes in marked populations. Environmental and Ecological Statistics Series Vol 3. Springer, New York, NY, p 617-637

Frederiksen M, Wanless S, Harris MP, Rothery P, Watson LJ (2004) The role of industrial fisheries and oceanographic change in the decline of North Sea black-legged kittiwakes. J Appl Ecol 41:1129-1139

Gaillard JM, Yoccoz NG (2003) Temporal variation in survival of mammals: a case of environmental canalization? Ecology 84:3294-3306

Grémillet D, Boulinier T (2009) Spatial ecology and conservation of seabirds facing global climate change: a review. Mar Ecol Prog Ser 391:121-137

Grémillet D, Lewis S, Drapeau L, van der Lingen CD and others (2008a) Spatial match-mismatch in the Benguela upwelling zone: Should we expect chlorophyll and seasurface temperature to predict marine predator distributions? J Appl Ecol 45:610-621

Grémillet D, Pichegru L, Kuntz G, Woakes AG, Wilkinson S, Crawford RJM, Ryan PG (2008b) A junk-food hypothesis for gannets feeding on fishery waste. Proc R Soc Lond B Biol Sci 275:1149-1156

Grémillet D, Mullers RHE, Moseley C, Pichegru L and others (2010) Seabirds, fisheries, and cameras. Front Ecol Environ 8:401-402

Hockey PAR, Dean WRJ, Ryan PG (2005) Roberts birds of southern Africa, 7th edn. John Voelcker Bird Book Fund, 
Cape Town

IUCN (2012) IUCN Red List of Threatened Species. Version 2012.1. www.iucnredlist.org. Downloaded on 24 July 2012

Klages N (1994) Dispersal and site fidelity of Cape gannets Morus capensis. Ostrich 65:218-224

Lebreton J, Burnham KP, Clobert J, Anderson DR (1992) Modeling survival and testing biological hypotheses using marked animals: a unified approach with case studies. Ecol Monogr 62:67-118

Lewis S, Grémillet D, Daunt F, Ryan P, Crawford RJM, Wanless S (2006) Using behavioural and state variables to identify proximate causes. Oecologia 147:606-614

Link WA (1999) Modeling pattern in collections of parameters. J Wildl Manag 63:1017-1027

Makhado AB, Crawford RJM, Underhill LG (2006) Impact of predation by Cape fur seals Arctocephalus pusillus pusillus on Cape gannets Morus capensis at Malgas Island, Western Cape, South Africa. Afr J Mar Sci 28:681-687

Mullers RHE, Navarro RA (2010) Foraging behaviour of Cape gannets as an indicator for colony health status. Endang Species Res 12:193-202

Mullers RHE, Navarro RA, Crawford RJM, Underhill LG (2009) The importance of lipid-rich fish prey for Cape gannet chick growth: Are fishery discards an alternative? ICES J Mar Sci 66:2244-2252

Ormerod SJ (2003) Current issues with fish and fisheries: editor's overview and introduction. J Appl Ecol 40:204-213

$>$ Piatt JF, Sydeman WJ, Wiese F (2007) Introduction: seabirds as indicators of marine ecosystems. Mar Ecol Prog Ser 352:199-204

Pichegru L, Ryan PG, van der Lingen CD, Coetzee J, RopertCoudert Y, Grémillet D (2007) Foraging behaviour and energetics of Cape gannets Morus capensis feeding on live prey and fishery discards in the Benguela upwelling system. Mar Ecol Prog Ser 350:127-136

Pichegru L, Ryan PG, Le Bohec C, van der Lingen CD and others (2009) Overlap between vulnerable top predators and fisheries in the Benguela upwelling system: implications for marine protected areas. Mar Ecol Prog Ser 391: 199-208

Pradel R, Hines JE, Lebreton JD, Nichols JD (1997) Capturerecapture survival models taking account of transients. Biometrics 53:60-72

Rolland V, Barbraud C, Weimerskirch H (2008) Combined

Editorial responsibility: Hans-Heinrich Janssen,

Oldendorf/Luhe, Germany effects of fisheries and climate on a migratory long-lived marine predator. J Appl Ecol 45:4-13

Rolland V, Weimerskirch H, Barbraud C (2010) Relative influence of fisheries and climate on the demography of four albatross species. Glob Change Biol 16:1910-1922

Rouault M, Penven P, Pohl B (2009) Warming in the Agulhas current system since the 1980s. Geophys Res Lett 36, L12602, doi: 10.1029/2009GL037987

> Rouault M, Pohl B, Penven P (2010) Coastal oceanic climate change and variability from 1982 to 2009. Afr J Mar Sci 32:237-246

> Roy C, van der Lingen CD, Coetzee JC, Lutjeharms JRE (2007) Abrupt environmental shift associated with changes in the distribution of Cape anchovy Engraulis encrasicolus spawners in the southern Benguela. Afr J Mar Sci 29:309-319

> Sandvik H, Erikstad KE, Barrett RT, Yoccoz NG (2005) The effect of climate on adult survival in five species of North Atlantic seabirds. J Anim Ecol 74:817-831

Shabangu F, Coetzee J, Merkle D, Mushanganyisi K (2011) Results of the 2011 spawner biomass survey. Department of Agriculture, Forestry and Fisheries. Fisheries/2011/ SWG-PEL/92

Skalski JR, Hoffmann A, Smith SG (1993) Testing the significance of individual- and cohort-level covariates in animal survival studies. In: Lebreton JD, North PM (eds) Marked individuals in the study of bird population. Birkhäuser Verlag, Basel, p 9-28

Staverees L, Crawford RJM, Underhill LG (2008) Factors influencing the breeding success of Cape gannets Morus capensis at Malgas Island, 2002/03. Ostrich 79:67-72

van der Lingen CD, Coetzee JC, Demarcq H, Drapeau L, Fairweather TP, Hutchings L (2005) An eastward shift in the distribution of southern Benguela sardine. GLOBEC Newsl 11:17-22

Velarde E, Ezcurra E, Cisneros-Mata MA, Lavin MF (2004) Seabird ecology, El Niño anomalies, and prediction of sardine fisheries in the Gulf of California. Ecol Appl 14: $607-615$

- White GC, Burnham KP (1999) Program MARK: survival estimation from populations of marked animals. Bird Study 46:S120-S139

Worm B, Lotze H, Jonsen I, Muir C (2010) The future of marine animal populations. Blackwell Publishing, Oxford

Submitted: November 23, 2011; Accepted: May 9, 2012

Proofs received from author(s): July 26, 2012 